\title{
A AULA DE MÚSICA ONLINE NO ENSINO SUPERIOR: CONSIDERAÇÕES EMERGENCIAIS SOBRE PEDAGOGIA E MOTIVAÇÃO EM TEMPOS DE PANDEMIA
}

\section{THE ONLINE MUSIC CLASS IN HIGHER EDUCATION: EMERGENCY CONSIDERATIONS ABOUT PEDACOGY AND MOTIVATION IN TIMES OF PANDEMIC}

\author{
Cássia Carrascoza Bomfim \\ Universidade de São Paulo \\ cassiacarrascozabomfim@usp.br \\ Eliana C. M. C. Sulpício \\ Universidade de São Paulo \\ elianasulpicio@usp.br \\ Fátima Corvisier \\ Universidade de São Paulo \\ fatimacorvisier@usp.br \\ Silvia Berg \\ Universidade de São Paulo \\ silviaberg@usp.br
}

\section{Resumo}

presente artigo apresenta algumas considerações sobre pedagogia e motivação nas aulas de música no Ensino Superior, abordando atividades realizadas nos anos letivos de 2020 e 2021, período correspondente à pandemia do Covid 19. Para tal, comentamos os termos relacionados à pedagogia e à motivação e descrevemos atividades aplicadas e vivenciadas nas aulas, que ilustram esta prática em interações emergenciais online.

Palavras-chave: Pedagogia; Motivação; Pandemia/Covid 19. 


\begin{abstract}
This article presents some considerations regarding pedagogy and motivation in music classes in Higher Education, addressing activities carried out in the 2020 and 2021 academic years, period corresponding to the Covid 19 pandemic. We have described activities applied and experienced in class, which illustrate this practice in an emergency online interaction.
\end{abstract}

Keywords: Pedagogy; Motivation; Pandemic/Covid 19.

\title{
Considerações iniciais
}

A atuação acadêmica do professor universitário compreende três vertentes: ensino, pesquisa e extensão. No caso do professor de música, há de se considerar também a vertente artística, que no nosso entender alinha-se ao ensino e a pesquisa, de forma integrada. No Departamento de Música da FFCLRP-USP, do qual fazemos parte, a missão principal é a música, entendida no contexto das artes, portanto com foco nas atividades artísticas em música.

A missão do DM-FFCLRP-USP é a música, entendendo-se a música entre as artes, e esta missão tem como foco as atividades artísticas em música (concertos de câmara e sinfônicos, música coral, vocal e instrumental, récitas de ópera, realização de eventos artístico-musicais el ou gravações audiovisuais de toda natureza, a música em interface com outras artes, trabalhos comunitários, produção de livros e demais publicações de pesquisas atreladas à performance musical, trabalhos de formação técnico-artística por meio de extensão universitária com impacto positivo na sociedade etc.), e a formação (já oferecendo graduação, e, com proposta para, num futuro próximo, oferecer também a pós-graduação profissional) de músicos artistas (compositores, instrumentistas, cantores, regentes e toda possibilidade de performance em música, incluindo-se a formação de professores em performance), para que possam atuar no mundo de trabalho artístico em 
música, tanto em arte como em arte popular, favorecendo seus fecundos desenvolvimentos com repercussão nacional $e$ internacional, já que a música é uma arte naturalmente internacionalizada, trabalhando-se com repertórios de todos os lugares e de todos os tempos, antigos ou contemporâneos, em fortes relações com a música no Brasil (PROJETO ACADÊMICO DO DEPARTAMENTO DE MÚSICA DA FFLCRP-USP, quinquênio 2019-2023, p. 3).

Nesse sentido, as atividades artísticas estão presentes também no conteúdo das disciplinas do currículo dos cursos oferecidos no DM, onde busca-se contemplar atividades de composição, improvisação e criação musical.

As artes, além da pesquisa (não obstante toda interface das pesquisas em artes com ciências da natureza, estudos culturais e questões filosóficas), contemplam ainda a invenção da obra (poiesis) e, em se tratando de arte essencialmente performática, justamente de sua interpretação-execução (práxis). $\bigcirc$ mundo do trabalho do artista, além de teórico, ou seja, além de envolver atividades de pesquisa, é também, e em primeira linha, prático-poético, o que diferencia sobremaneira suas condições profissionais. A performance, ou seja, a atividade artística por excelência em música, é sua condição diferenciada prático-poética. A performance compreende toda interpretação-execução, incluindo-se a composição, em música (PROJETO ACADÊMICO DO DEPARTAMENTO DE MÚSICA DA FFLCRP-USP, quinquênio 2019-2023, p. 4).

\section{Do ensino}

Nos anos de 2020 e 2021, dada a situação da pandemia do Covid-19, nós professores tivemos que, seja no ensino do instrumento, no ensino teórico e/ou prático de sala de aula, buscar novas formas de motivar nossos alunos e cumprir as metas estabelecidas no projeto 
pedagógico do curso. Concordamos que a reflexão sobre o ensino, paralelamente à pesquisa e extensão universitária, deva ser uma constante na carreira docente. A esse respeito, Gil (2012, p. 1) menciona que na formação do professor universitário, ficam claras as deficiências didáticas apontadas pelos estudantes, e que a preocupação com a preparação de pesquisadores por parte das autoridades educacionais é maior que com a preparação de seus conhecimentos pedagógicos.

Durante muito tempo prevaleceu no âmbito do Ensino Superior a crença de que, para se tornar um bom professor neste nível, bastaria dispor de comunicação fluente e sólidos conhecimentos relacionados à disciplina que pretendesse lecionar. A justificativa dessa afirmação fundamentava-se no fato de o corpo discente das escolas superiores ser constituído por adultos, diferentemente do corpo discente do ensino básico, constituído por crianças e adolescentes. Aliás, o próprio termo pedagogia tem sua origem relacionada à palavra criança (em grego: paidos = criança; gogein = conduzir). Os estudantes universitários por já possuírem uma "personalidade formada" e por saberem o que pretendem, não exigiriam de seus professores mais do que competência para transmitir os conhecimentos e para sanar suas dúvidas. Por essa razão é que até recentemente não se verificava preocupação explícita por parte das autoridades com a preparação de professores para o Ensino Superior. Ou melhor, preocupação existia, mas com a preparação de pesquisadores, ficando subentendido que quanto melhor pesquisador fosse mais competente professor seria (ClL, 2012, p. 1).

Nas reflexões no âmbito do ensino de música, Ray (2018) apresenta o uso dos termos "pedagogia”, "didática”, “ensino", “método" e "técnica" na visão da performance musical. A autora apresenta as implicações desses termos com os conceitos relacionados à prática docente na área de performance em música, contextualizando-os, com a intenção de oferecer à comunidade musical uma reflexão sobre a aplicação desses termos no processo pedagógico. De acordo com Ray (2018, p. 1) "como um termo que trata da educação, a pedagogia diz

\section{8}

REV. TULHA, RIBEIRÃO PRETO, v. 7, n. I pp. 105-130, jan.-jun. 2021 
respeito tanto ao ensino quanto às bases filosóficas que norteiam sua teoria e prática". Para a autora, o pensamento que norteia as escolhas de métodos e materiais em um processo de ensino, refere-se à visão pedagógica, e quanto mais se conhece estas visões que fundamentam uma determinada prática de ensino, melhor é o resultado na relação entre as ações estabelecidas pelo docente e suas concepções (RAY, 2018 , p. 1). Fonseca (2011, p. 131) expõe estratégias e técnicas para a otimização da prática musical. A autora apresenta várias considerações sobre a prática efetiva e deliberada e uma série de estratégias que vão desde a prática individual, a seleção e organização de atividades, o estabelecimento de objetivos e metas, a administração do tempo, até estratégias relacionadas aos estados mentais de ensaios, como gerenciar partes de difícil execução, preparação para apresentação pública, bem como exercícios físicos e Técnica de Alexander. Com este texto, a autora mostra a importância das reflexões relacionadas à pedagogia musical, evidenciando a vasta literatura em língua inglesa sobre o assunto (cf. FONSECA, p. 131-151).

\section{O termo motivação}

Todorov e Moreira (2005, p. 120) explicam que o termo motivação, assim como aprendizado, é largamente utilizado em compêndios de psicologia, e tal qual o termo aprendizagem, é utilizado em diferentes contextos, podendo assumir diversos significados. Portanto, seus usos na psicologia, psicometria e na teoria da aprendizagem são distintos. Nesse sentido, os autores elencam uma série de definições de motivação, exemplificando esta diversidade no trato do conceito (cf. TODOROV e MOREIRA, 2005, p. 122). Segundo os autores, estas abordagens apresentadas são muitas vezes contraditórias e apontam para a falta de conhecimento na área. Para Bzuneck (apud ARAÚJO, 201 1, p. 1 1 1) a ideia que se aplica ao termo motivação tem origem na raiz etimológica da palavra que vem do verbo latino movere, que dá 
origem a motivum ou "motivo". Sendo, portanto, a motivação "um elemento que gera uma ação, que move a pessoa na realização de uma função específica" (BZUNECK, apud ARAÚJO, p. 11 1). De acordo com Condessa (2010, p. 652) "os fatores envolvidos no processo motivacional do aluno perpassam tanto por suas emoções e percepções quanto pela interação com as pessoas que convivem". Condessa diz que:

Alguns pesquisadores consideram a motivação como um processo e não como um produto da aprendizagem. Ou seja, considerando-se que o processo motivacional do aluno não é passivel de se observar diretamente, Pintrich e Schunk (1996, p. 4) afirmam que "podemos inferi-lo através de comportamentos como a escolha das tarefas, do esforço, da persistência, e das verbalizações [...]" (CONDESSA, 2010 , p. 652).

Independentemente da acepção utilizada, é possivel observar que a motivação movimenta o indivíduo para a ação e é um fator importante na aprendizagem. "A forma como o educando percebe o ambiente à sua volta influi na sua capacidade de aprender" (PEREIRA at al., 2014). Neste sentido, Stipek (1996, apud ALVES, 2013, p.19) "observou, em sua pesquisa, que o ambiente em sala de aula pode ser fundamental para estimular o aprendizado do aluno em um domínio".

A motivação e o ensino da música também são tratados em Araújo (201 1, p. | | 1 - 130). Segundo a autora, "a motivação está presente em todo tipo de atividade humana, direcionando as ações e escolhas dos sujeitos" (ARAÚJO, 2011 , p. 111). Araújo considera a motivação, elemento fundamental para a aprendizagem musical. $\bigcirc$ estudo da motivação na aprendizagem musical representa um significativo campo de investigação, uma vez que, por meio de diferentes enfoques, podese obter resultados que auxiliem os educadores a compreender o percurso da aprendizagem discente, revelados por meio de dados sobre os aspectos pessoais dos sujeitos, o grau de tal envolvimento

\section{0}

REV. TULHA, RIBEIRÃO PRETO, v. 7, n. I pp. 105-130, jan.jun. 2021 
e as consequências e resultados de atividades musicais na relação intrínseca e extrínseca (ARAÚJO, 2011 , p. 111).

Isto posto, no ano de 2020 e 2021, como mencionado anteriormente, dada a pandemia do Covid-19, nos deparamos de forma repentina com uma nova situação que mudou radicalmente as interações presenciais das aulas para interações online. Tivemos que nos adaptar rapidamente e, nesta adaptação, surgiram então algumas perguntas básicas: Como manter um ensino de qualidade? Como manter o aluno motivado? Como conciliar as metas departamentais associadas às novas tecnologias? Como será o ensino daqui para frente, quando retornarmos ao presencial? Será ele híbrido, guardada suas devidas singularidades?

\section{Do uso das TICs 1}

Gohn (2020, p. 157), menciona que:

O cenário da pandemia de Covid-19 no início de 2020 apresentou enormes desafios para a educação, em todo o mundo. Com a necessidade de distanciamento social, recomendado pela Organização Mundial da Saúde e amplamente divulgado nos meios de comunicação, muitos professores foram colocados frente à demanda de dar continuidade a suas aulas à distância, em alguns casos sem ter nenhuma experiência anterior nessa modalidade de ensino. Dessa forma, não houve o devido tempo para planejamento, preparação de materiais, para o aprendizado sobre as tecnologias envolvidas e principalmente sobre as pedagogias inerentes ao trabalho à distância. $\mathrm{Na}$ área da música, o desafio tornou-se exacerbado pelas diversas especificidades das disciplinas, particularmente

I Tecnologias da Informação e Comunicação (TICs) no campo da educação podem ser descritas como um conjunto de ferramentas tecnológicas (computador pessoal, celular, câmera de vídeo, gravador de áudio, softwares, plataformas digitais de dados, etc.) que proporcionam meios de acesso ao conhecimento e facilitam o binômio ensino-aprendizagem.

\section{1}

REV. TULHA, RIBEIRÃO PRETO, v. 7, n. I pp. 105-130, jan.-jun. 2021 
naquelas em que estão envolvidos aspectos práticos com instrumentos musicais (COHN, 2020, p. 153).

Gohn (2020, p. 152), também aponta uma "diferenciação entre ações de ensino remoto realizadas de forma emergencial e a educação a distância (EAD), quando aplicada com planejamento, pedagogias especificas e condições tecnológicas favoráveis". Este segundo grupo de ações já vem sendo realizado há algum tempo, na modalidade mencionada (cf. COHN, 2020). No entanto, a situação emergencial ocorrida nos últimos dois anos, foi algo novo no dia a dia da maioria dos professores de música.

Todos foram forçados a atuar em esquema de ensino remoto emergencial, em geral priorizando o formato síncrono e tendo como base softwares projetados para a voz falada, apesar das deficiências já apontadas. Um novo quadro se desenhava, no qual professores e alunos teriam que se adaptar aos estudos mediados por meios tecnológicos, em tempo real (COHN, 2020, p. 157).

Para manter a motivação dos alunos e cumprir as metas do Projeto Pedagógico do DM, conciliando todos os pontos levantados neste texto, apresentamos a seguir, algumas atividades realizadas nas disciplinas ministradas online com ações emergenciais síncronas e assíncronas.

\section{Das atividades Improvisação livre}

A improvisação livre é uma atividade que vem sendo utilizada com frequência em algumas disciplinas do departamento. Na disciplina 
de Percepção Musical, ela integra os recursos pedagógicos e mecanismo de motivação dos alunos, pois em função de observações de pesquisadores da área, sentimos a necessidade de implementar as atividades realizadas.

A pesquisadora Otutumi, em sua dissertação de mestrado (2008) e em sua tese de doutorado (20/3), investiga a situação da disciplina de Percepção Musical no âmbito dos cursos superiores de música no Brasil. Inicialmente, em sua dissertação de mestrado, a autora observa a estrutura e o perfil curricular da disciplina, atentando-se à quantidade de docentes, de alunos por sala de aula, de horas de aula e às opiniões quanto aos cuidados pedagógicos da matéria. Em sua tese de doutorado, a autora traz muitas contribuições e reflexões a respeito de propostas para melhorias da disciplina no ensino superior. $\bigcirc$ que observamos nos estudos de Otutumi é que, em ambos os textos, a autora mostra uma preocupação quanto aos aspectos pedagógicos utilizados na disciplina, ressaltando a falta de motivação dos alunos. $\bigcirc$ uso da criação musical nas atividades de ensino musical vem sendo utilizado por educadores de várias gerações. Orff, Dalcroze, Kodaly, Martenot, Schafer, Swanwick e outros mais, sempre fizeram uso das práticas criativas em sala de aula. Esther Scliar (PAZ, 2013, p. 83) ressalta em sua metodologia a importância dada à criação, improvisação e composição. Scliar se referia a estas atividades com o termo "invenção". Termo preferido de Scliar, tinha "lugar cativo em sua prática junto aos alunos" (PAEZ, 2013, p. 83). Para Koellreutter (in BRITO, 2015, p. 76), “a criação musical tem sentido na relação com o jogo da consciência e o artista tem de ser um aventureiro, no bom sentido. Tem que criar, inventar, algo que não existia, o que é uma aventura" (KOELLREUTTER, in BRITO, 2015, p. 75). Giorgetti (2018), em sua dissertação de mestrado intitulada "Práticas pedagógicas de auxillio ao desenvolvimento da escuta musical na disciplina de percepção musical", reflete sobre as muitas formas de dinamizar a aula de percepção. Dentre as propostas expostas pelo autor, estão também a improvisação e a composição.

\section{3}

REV. TULHA, RIBEIRÃO PRETO, v. 7, n. I pp. 105-130, jan.-jun. 2021 
Bortz (2010) menciona o fato de que nas aulas de percepção há uma falta de integração entre os exercícios práticos e o produto musical e, Covington e Lord (1994, apud BORTZ, 2010, p. 1-2) mencionam que "enquanto as pesquisas em cognição musical têm se desenvolvido consideravelmente nos últimos anos, o treinamento auditivo em sala de aula tem sido frustrante para professores e alunos". Ainda segundo Bortz, as abordagens objetivistas e construtivistas podem coexistir, no entanto, "a abordagem exclusivamente objetivista está na falta do exercício da transferência de um domínio a outro" (BORTZ, 20 10, p. 7).

Uma fórmula aritmética não é, em si, um problema ao estudante de matemática. $\bigcirc$ problema é não ser oferecido ao aluno o conhecimento de sua origem, a informação: 'de onde vem?' Se, ao contrário, como professores e pesquisadores, oferecermos aos alunos a possivel conexão às texturas complexas da música, respeitando suas próprias experiências e dirigindo-as de maneira que eles mesmos possam aplicá-las em seu treinamento auditivo, o estudo da percepção pode se tornar menos árido e mais interessante (BORTZ, 2010, p. 7).

Costa aponta estratégias de escuta no contexto da improvisação livre. Para o autor, a improvisação livre "pode ser considerada uma espécie de música concreta" (COSTA, 2016, p. 87). No entanto, o autor ressalta não fazer alusão à musique concrète instrumentale de H. Lachennman, embora, segundo o autor, existam "pontos de contato entre a livre improvisação e as experiências radicais desse compositor com relação a utilização dos instrumentos" (cf. COSTA, 2016, p. 87). Para Costa, preparar um ambiente adequado para a realização das práticas da improvisação livre, "acarreta uma série de pressupostos, dentre os quais se destacam a intencionalidade e o desejo, a disposição para a criação coletiva (que prevê a interação), a disponibilidade de enfrentar riscos e um tipo de escuta intensificada" (COSTA, 2016, p. 87). Portanto, a improvisação livre na aula de percepção musical torna-se uma ferramenta interessante e de grande valia para todos os

\section{4}

REV. TULHA, RIBEIRÃO PRETO, v. 7, n. I pp. 105-130, jan.jun. 2021 
envolvidos. Com estas atividades, observamos que os alunos envolvidos se tornam mais participantes e passam a desenvolver um tipo de escuta especifica.

Anteriormente, em aulas presenciais, uma das formas aplicadas consistiu em convidar os alunos a um exercício de improvisação livre conduzida, baseado na experiência proposta por Schafer (1991, p. 36). Nessa proposta, sinais previamente acordados foram mostrados pela professora com intuito de indicar parâmetros de sons como duração, dinâmica, intensidade, dentre outros. Em uma espécie de jogo, onde as escolhas individuais iam desde o uso de instrumentos, voz el ou ruídos, criou-se um tecido sonoro. Em seguida dividiu-se o grupo em dois e um aluno foi convidado a reger simultaneamente o segundo grupo, tentando estabelecer uma relação dialógica entre os grupos, sem um compromisso com o resultado, mas com o atributo de que, como afirma Costa "o que importa é, em primeiro lugar, a própria substância concreta e posteriormente uma espécie de gramaticalidade que se forja no processo e que diz respeito à estruturação e ao encadeamento dos valores propriamente musicais" (COSTA, 2016, p. 32). Finalmente separou-se a classe em três grupos, com a proposta de cada grupo realizar uma improvisação. A cada performance foram enumerados itens estruturais que emergiram da experiência, tais como imitação, sessões, ponto culminante e estruturas rítmicas. A experiência foi considerada pelos alunos como bastante motivadora.

No atual contexto, converter ações similares para realizações online tornou-se desafiador. Em 2020, a partir do isolamento social, para a disciplina de percepção melódica e harmônica, adotamos como ferramenta a plataforma Zoom, que embora seja desenvolvida para o discurso vocal, dispõe de configurações para melhoria da qualidade sonora na comunicação e vem sendo aprimorada de maneira que oferece uma série de recursos específicos para a atividade musical. 
Com a intenção de explorar as possibilidades de ensino e aprendizagem nessa realidade, passamos a pesquisar os parâmetros de performance, escuta e participação de audiência em ambiente virtual. Para tal, propusemos aos alunos a realização da performance da obra 4'33" de John Cage de 1952. Trata-se de uma obra composta em três movimentos, que tem em sua duração completo silêncio. Em performances realizadas presencialmente, todos os sons que acontecem dentro da sala de espetáculo, e que são externos à performance dos músicos, criam um contexto sonoro único. Para a experiência no ambiente virtual, abrimos todos os microfones dos alunos, assistimos e gravamos a performance do duo de flauta e violoncelo, simulando a situação da performance ao vivo. A gravação de áudio filtrou ruídos, tosses, cachorros latindo, entre outros elementos sonoros da realidade dos participantes. Alguns sons registrados são indefiníveis, e a não sobreposição dos sons simultâneos evidenciou a limitação de difusão polifônica da plataforma Zoom.

Além disso, ficou patente que poderíamos usar as TICs com um direcionamento para a performance musical criativa e ampliar o sentido da percepção em ações que transcendam os limites do espaço físico do palco.

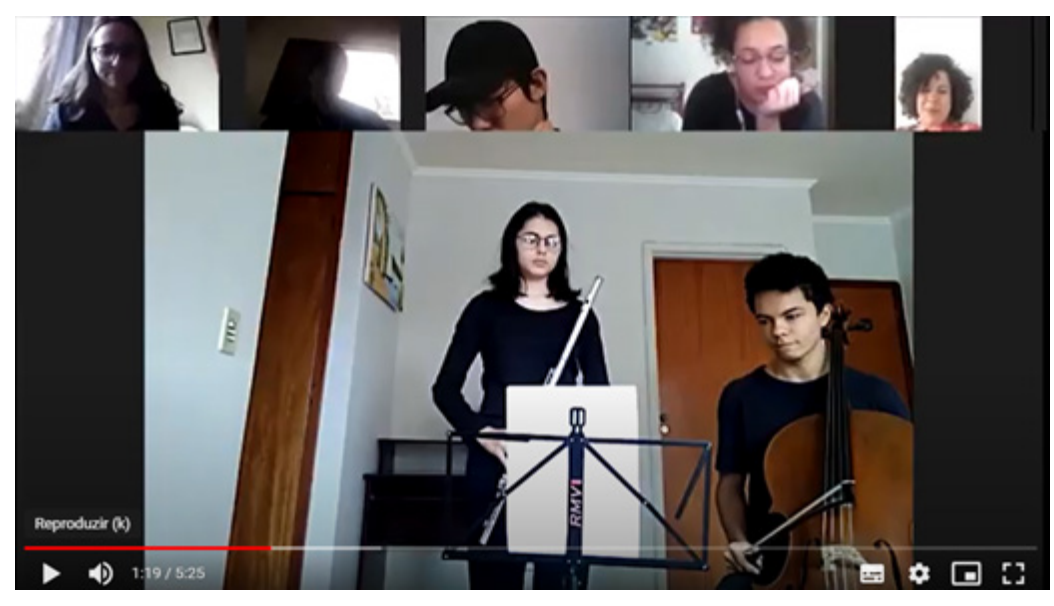


Figura I: Imagem da performance virtual de 4'33"de J. Cage, pelos alunos Beatriz Faleiros (flauta) e Vinícius Roetgher (violoncelo), acima alunos da classe como público, na atividade desenvolvida na disciplina de percepção.

Propusemos uma atividade de criação audiovisual a partir dos conceitos de paisagem e polvição sonoras e de escuta desenvolvidos por Schafer: "A paisagem sonora do mundo está mudando. Nosso ambiente acústico está mudando radicalmente. Esses novos sons diferem em qualidade e intensidade daqueles do passado. A polvição sonora é hoje um problema mundial" (SCHAFER, 1977, p. 17).

Ainda exibimos do autor, o vídeo "Listen"2, no qual Schafer exibe sua própria paisagem sonora, demonstrando a escuta ativa. Este vídeo é construido sobre narrativas audiovisuais que exemplificam e enfatizam os conceitos levantados pelo autor. Também exibimos um vídeo contendo o extrato da entrevista com John Cage, para o documentário "Écoute", realizado em 1991, em Nova lorque. Nele o compositor fala sobre sua maneira de escuta, de percepção das propriedades do som, do ruído, do silêncio e trata também das relações de diferentes artes com conceitos de tempo e espaço. Baseado nos trabalhos de Schafer e Cage, foi feita uma proposta de trabalho individual para a classe de percepção, que apresentou resultados positivos. A proposta foi baseada nos seguintes critérios: escutar atentamente a paisagem sonora presente nos espaços internos e externos das casas, uma vez que todos estávamos limitados pelo isolamento social; definir uma maneira de registrar essa realidade sonora; compor um trabalho audiovisual produzido com as ferramentas disponíveis, como telefones celulares, editores de áudio e vídeo em plataformas gratuitas.

Esse trabalho promoveu a percepção auditiva em parâmetros diferenciados, e foi realizado com o uso de TICs. Vários alunos

2 https://youtu.be/pL8yo8 I KaWg

3 https://youtu.be/Hj7rg-gEzgo 
produziram vídeos contendo a própria performance em seus instrumentos, composições, improvisações, sobreposições de ruidos e falas.

A composição audiovisual da aluna Cabriela Oliveira foi estruturada sobre camadas de sobreposição de eventos sonoros e de imagens: performance ao violoncelo de improvisação, sons da rua, miado do seu gato; declamação da poesia "O Guardador de Rebanhos" de Fernando Pessoa; imagens do interior de seu quarto e da vista de sua janela; em períodos diferentes do dia.

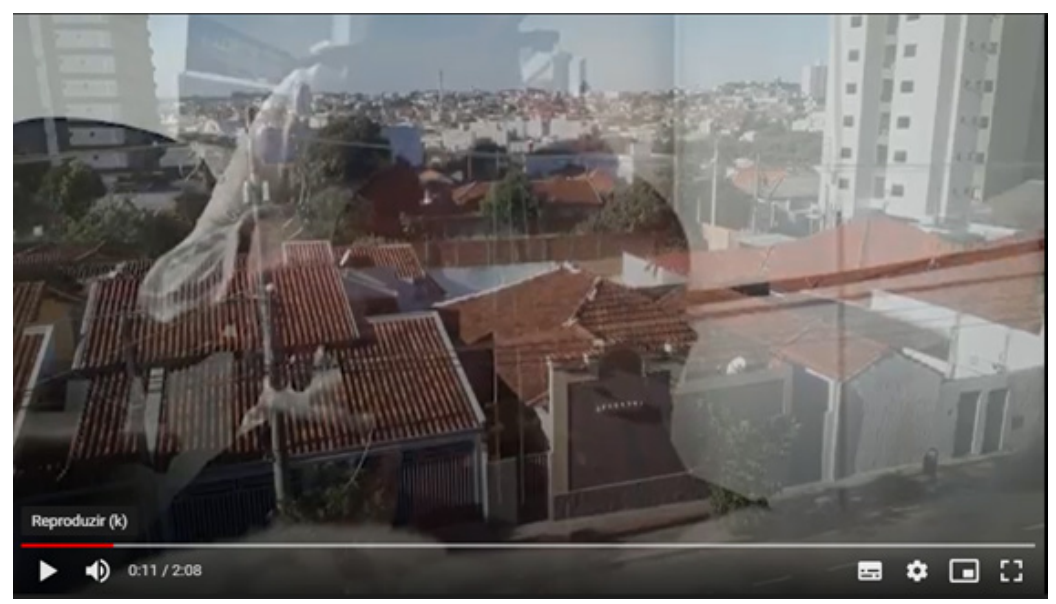

Figura 2: Imagem do trabalho audiovisual da aluna Gabriela Oliveira, sobre a paisagem sonora durante $\mathrm{O}$ isolamento, atividade proposta para a disciplina de percepção.

\section{Composição}

Outra atividade que vem sendo aplicada em diversas disciplinas há algum tempo, com resultados positivos, é a elaboração e execução de composições dos alunos. Para Swanwick (2003, p. 68) "a composição é uma necessidade educacional, não uma atividade opcional para se desenvolver quando o tempo permite. Ela dá ao aluno 
uma oportunidade para trazer suas próprias ideias à microcultura da sala de aula, fundindo educação com a música de fora". Shafer (1997, 2009) propõe uma série de atividades criativas para a escuta e criação musical, que são diferentes das encontradas no ensino tradicional.

Um exemplo de uma proposta que foi aplicado em sala de aula no ano de 2019 na disciplina de percepção rítmica, se baseou em escolher um estudo rítmico do Manual de Rítmica do autor Abelardo Mato Alonso e, com base na estrutura rítmica estabelecida exercício, criou-se uma composição completa para ser executada também em sala de aula. Formaram-se grupos de cinco ou seis alunos e direcionamentos $e$ instruções de como escolher a gama de alturas sonoras a serem usadas foram dadas pelo professor, com o intuito de auxiliar os alunos no processo de composição. Eles puderam escolher as diferentes linguagens sonoras que compreendem as correntes estéticas da música, optando entre o sistema tonal, modal, atonal, dodecafônico, aleatório, bem como outras vertentes. A instrumentação foi livre, ficando a critério de cada grupo. Depois de terminada a composição e a escrita da partitura, realizou-se a apresentação de todas as composições em sala de aula. Um dos alunos do grupo encarregou-se da regência, enquanto os demais executaram a peça. $O$ resultado de tais experiências apontou para uma maior participação, bem como uma melhor compreensão e assimilação dos ritmos por parte dos alunos.

Para mantermos a atividade de criação online, uma proposta, que trouxe resultado positivo, foi a composição e execução de uma peça para grupo de percussão, por alunos da disciplina Música de Câmara. A proposta foi baseada nos seguintes critérios: compor uma peça para grupo de percussão com três executantes, com duração de no máximo três minutos; utilizar apenas instrumentos disponíveis em casa, uma vez que, por conta da pandemia, não se teve acesso aos instrumentos da escola; elaborar a edição da partitura; executar e gravar para disponibilizar externamente a USP. $\bigcirc$ trabalho realizado 
resultou na produção da peça Percussion under Construction, do aluno Uladimir José Servo (conhecido como Magrin Ribeiro), disponível em um vídeo que pode ser visto no site indicado ${ }^{4}$, bem como na produção da partitura em programa de computador. Todo o trabalho foi desenvolvido de forma virtual, e somente a gravação final foi realizada presencialmente, com as devidas normas de segurança.

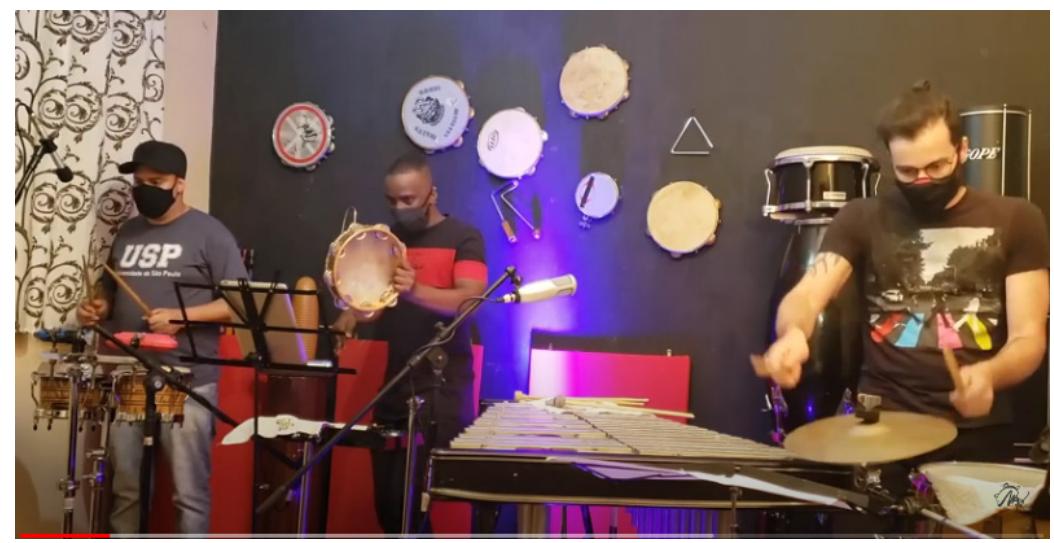

Figura 3: Imagem da execução dos alunos na atividade de composição solicitada para a disciplina Música de Camara. Compositor e executante: Magrin Ribeiro (à esquerda). Executantes, (da esquerda para a direita): Matheus Andrade e Ricardo Bovo. Todos são membros do GRUPURI 5 .

Nesse cenário, o uso das TICs confirmou a sua importância como ferramenta de continuidade de muitos dos trabalhos que eram realizados somente de forma presencial. Atualmente, por meio dessas tecnologias, o processo de aprendizado dos graduandos é mantido, assim como a assistência à comunidade, mantendo o devido distanciamento social e proteção a todos os envolvidos.

As disciplinas de Criação Musical de l e || direcionaram suas atividades para a produção, tanto de materiais didáticos, muitos

4 Disponivel em: https://www.youtube.com/watch?v=OrzeyjwhqOE

5 Grupo de percussão do DM-FFCLRP-USP. 
diretamente alinhados com as necessidades da comunidade $e$ realidade local dos discentes, diretamente ligadas às atividades que estes exerceram e exercem primordialmente através de meios digitais, atuando como professores, orientadores e coordenadores de cursos, quanto às atividades de criação de arranjos e transcrições que pudessem ser adaptadas e executadas durante a pandemia, de acordo com as necessidades e realidades enfrentadas pelos discentes, principalmente em suas respectivas residências ou em grupos muito reduzidos, e que, em muitos casos, também continham elementos comuns às duas propostas, servindo tanto como arranjo ou transcrição com possibilidade de performance em concerto gravado ou, em seu devido tempo, presencial, ou como material didático-pedagógico.

A transcrição idiomática de um instrumento, voz e/ou grupo de instrumentos para outro(s), pode ter implicações complexas de adaptação, considerações sobre troca de registros e timbres, e principalmente redução ou ampliação tímbrica, melódica, harmônica, resultando em transformações algumas vezes radicais de espectros sonoros, sem que, no entanto, a essência da obra seja alterada. As aulas onlinel sincrônicas, com discussões teórico-musicais no início da aula, e exposição de trabalhos acessiveis a todos os participantes na segunda parte da aula, foram dessa forma, concentradas na relação essência musical - transposição - exequibilidade/organicidade performance, relações essas essencialmente interdisciplinares, e de cuja fusão criaram-se novos horizontes e possibilidades de atuação e trabalho, uma vez que parte das obras transcritas foram para um instrumental ou grupo instrumental/vocal possivel dentro das limitações impostas pela pandemia Covid-19.

A criação de arranjos que se seguiu às transcrições, pressupôs, um trabalho de elaboração maior, na medida em que materiais derivados foram utilizados para introduções, interlúdios e codas, em relações de maior ou menor desdobramentos, com a essência da obra, desde a criação fiel às obras originais, às criações mais elaboradas 
com modificações métricas e derivações do material original mais distantes do modelo utilizado.

Com relação à criação de materiais didáticos, ainda em andamento, de posse das experiências citadas acima, elaborou-se uma sequência de questões técnicas a serem abordadas vocal el ou instrumentalmente, com um aprofundamento de especificidades técnicas relativas a seus respectivos graus de dificuldade de execução organicamente relacionados a cada voz ou instrumento a ser tratado. Definiu-se ou criou-se o material básico a ser desenvolvido e suas aplicações aos itens selecionados para o tratamento e criação didática e suas relações músico-pedagógicas. Como estas atividades ainda estão em desenvolvimento, não há ainda partituras ou gravações completas disponíveis.

Outra disciplina que teve seu desenvolvimento alterado pela TICs foi a disciplina de Regência Coral, que teve que ser reformulada rapidamente de essencialmente presencial para totalmente onlinel sincrônica. Nesse sentido, o peso maior da disciplina anteriormente direcionada à técnica de regência e à sua práxis imediata em grupos vocais e/ou instrumentais, passou a ser concentrada na partição da função do regente como líder e preparador, suas funções pedagógicas e administrativas, e sua atuação por meios digitais. Nessa partição, uma das funções imediatamente complementares à técnica de regencia (e vice-versa), a de preparação vocal e/ou instrumental e o mapeamento e preparação de ensaios e percurso em direção à realização de apresentações e concertos presenciais ou digitais adquiriu uma dimensão muito maior do que projetada nas aulas presenciais, uma vez que se tornou o meio para vídeos de coaching em auxílio a aulas e orientações online ministradas pelos discentes. Nessa modalidade de coaching online, que vem sendo desenvolvida e aperfeiçoada principalmente no período de pandemia/Covid 19, como desdobramento das técnicas de ensaio, especialmente desenvolvidas para atividades online, destacamos a participação da discente Bartira

\section{2}

REV. TULHA, RIBEIRÃO PRETO, v. 7, n. 1 pp. 105-130, jan.-jun. 2021 
Sene ${ }^{6}$, integrando pesquisa, análise, mapeamento de ensaio e coaching online. $O$ trabalho desenvolvido pela aluna Bartira pode ser visto no site indicado abaixo?.

\section{Gravação Audiovisual - desenvolvimento da audição crítica}

A audição crítica, entendida como aquela em que o performer tem o controle sobre a produção sonora e é capaz de se ouvir e julgar o resultado obtido é, sem dúvida, uma das habilidades conquistadas mais tardiamente pelos alunos de música. Ela tem como resultado o controle sobre seu instrumento musical, mas, antes de tudo, significa - amadurecimento da audição interior, a soma dos conhecimentos musicais adquiridos e transpostos para a performance e o domínio das habilidades que compõem a área da chamada percepção musical.

O formato remoto de ministração de aulas de instrumento, no caso, aulas de piano, acarretou uma série de problemas, de natureza variada, mas também possibilitou soluções que transformaram as práticas de estudo dos alunos e os fizeram ser mais rigorosos em suas autoavaliações, contribuindo para o melhor desenvolvimento de sua audição crítica.

As aulas semanais foram mantidas e ministradas de forma síncrona. Como em uma aula presencial, foram conservados os procedimentos habituais: a chegada do aluno "em classe", a performance da(s) obra(s) em aula, avaliação e discussão dos resultados junto ao professor

\footnotetext{
6 Bartira Sene é cadeirante; nasceu com Artrogripose Múltipla Congênita. A atividade de coaching online pode ser desenvolvida por todos os discentes. Nesse caso específico de atividade, Bartira adaptou-se admiravelmente bem a esta atividade, vindo a desenvolver criativa e musicalmente as possibilidades de coaching online. Dessa forma, esta e outras atividades correlatas também podem e poderão servir para atividades integradoras e agregadoras de discentes com ou sem deficiências físicas.
}

7 https://youtu.be/QltQROB2DrM 
e novas performances para trabalhar as novas ideias. Como o uso de plataformas de videoconferência para aulas de piano síncronas acarreta problemas de qualidade sonora, optou-se pelo uso de performances pré-gravadas das obras em estudo. Esse procedimento foi revelador para os alunos. Ao contrário de uma performance live, efêmera, o material para as aulas ficaria gravado em audiovisual (permanente!), e isso provocou uma busca pela perfeição (não apenas evitando-se erros, mas em busca de uma sonoridade melhor, de ideias mais claras, de maior convicção interpretativa) o que se traduziu em mais horas de estudo, maior empenho, disciplina e propósitos mais claros a serem atingidos na prática diária. Porém, ainda mais significativa foi a perplexidade de cada aluno ao descobrir, por meio das infinitas gravações de uma obra, o que realmente era o resultado de sua performance: não aquela imaginada, mas a real. Em um primeiro momento, a motivação foi um fator preocupante, pois para muitos o choque de realidade poderia influenciar negativamente na crença do senso de competência e autoeficácia. Como cita Hackett ( 1995, apud PARNCUTT E MCPHERSON, 2002, p. 34), “a percepção da competência pessoal é tão poderosa que pode influenciar na motivação e em futuras decisões quanto a continuar ou não na carreira".

Usando de estratégias de ensino nas quais o aluno e não o professor, ou mesmo o próprio conteúdo, são o foco da aula, foi iniciada uma prática de repetidas audições do material musical estudado, em trechos curtos, para que os alunos pudessem avaliar com o professor todos os aspectos da performance, bons e "menos bons", no intuito de desenvolver suas qualidades auditivas. É necessário esclarecer que diz respeito a uma audição qualitativa: a percepção da qualidade do som (toques, articulação, dinâmica, pedal, velocidade do ataque e da retirada das notas) e não apenas ao reconhecimento de alturas; do reconhecimento rítmico, métrico, hipermétrico, agógico, e tudo o que essa percepção implica no entendimento do discurso musical; a relação do resultado sonoro esperado com os gestos que o tornam possível

\section{4}

REV. TULHA, RIBEIRÃO PRETO, v. 7, n. I pp. 105-130, jan.-jun. 2021 
(técnica pianística). Enfim, todos os aspectos de que se compõe a performance pianística. Tais estratégias, ainda que sempre utilizadas nas aulas presenciais, surtiram um grande efeito nas aulas remotas, pois a análise meticulosa dos trechos de uma mesma gravação, diferentemente da performance ao vivo do aluno e da modelagem que o professor, em geral, emprega nas aulas presenciais, tornou o aluno o avaliador "externo" daquela ação. As várias repetições de um determinado trecho, ouvidas com o professor, no qual a cada momento a atenção do aluno enquanto avaliador/ouvinte era direcionada para um novo aspecto, levou ao aumento da consciência desses aspectos $e$, consequentemente ao aumento da audição interior (habilidade em imaginar de antemão a produção sonora) e da audição crítica (habilidade em avaliar o resultado obtido) dos vários alunos. Essa prática foi transferida também para o estudo diário, o que foi muito proveitoso.

Após um período de adaptação ao novo formato de aula, pode-se concluir que esse primeiro choque de realidade foi superado e por conta das sucessivas sessões de gravação (sempre através de câmara de celular) e revisão dessas gravações (sempre realizadas em audiovisual), os alunos tiveram consciência da melhoria de suas habilidades auditivas, compreenderam ainda mais o sentido de um estudo realizado com atenção, concentração e com propósitos objetivos, diferentemente da repetição indefinida e sem sentido. Mesmo após o retorno presencial, uma vez que tenhamos o final ou abrandamento da pandemia da Covid-19, manteremos essa estratégia de gravação e apresentação de material audiovisual como atividade extra de estudo para aprimoramento da performance.

\section{Considerações finais}

A visão dos alunos foi obtida por meio de diálogos não formais de forma coletiva e individual e o que se pode perceber é 
que através da observação dos resultados das atividades que foram aplicadas em sala de aula online, e tendo como embasamento teórico os diversos autores citados, podemos concluir que as experiências realizadas durante o período de pandemia poderão e deverão ser integradas a modelos híbridos ou presenciais com sucesso, trazendo assim contribuições importantes ao curso, à formação dos discentes e à comunidade.

\section{Referências}

ARAújo, R. C. Motivação e ensino de música. In: ILLARI, B. S.; ARAÚjO, R. C. (orgs). Mentes em Música. 2.ed. Curitiba: UFPR, 2013.

BORTZ, C. Contextualização Musical no Treinamento Auditivo: Transferindo Memorias a Prática Musical. In: Anais do VI Sincam, 2010, Rio de Janeiro, 1-8.

BRITO, T. A. Hans-Joachim Koellreutter: ideias de mudo, de música, de educação. São Paulo: Peirópolis, Edusp, 2015.

CONDESSA, J. A motivação dos alunos para continuarem seus estudos em música. In: Anais do VI Sincam, 20 10, Rio de Janeiro, 65 I-66 I.

COSTA, R. Música Errante: o jogo da improvisação livre. São Paulo: Perspectiva, 2016.

FONSECA, D. S. Estratégias e técnicas para otimização musical: algumas contribuições da literatura em lingua inglesa. In: ILLARI, B. S.; ARAÚJO, R. C. (orgs). Mentes em Música. 2. ed. Curitiba: UFPR, 2013.

GIL, A. C. Didática do Ensino Superior. 7.ed. São Paulo: Atlas, 2012.

COHN, D. M. Aulas online de instrumentos musicais: novo paradigma em tempos de pandemia. REV. TULHA, RIBEIRÃO PRETO, v. 6, n. 2, pp. |52-17|, jul.-dez. 2020.

OTUTUMI, C. H. V. Percepção Musical: situação atual da disciplina nos cursos superiores de música. Campinas, 2008. 238f. Dissertação (Mestrado em Música). Instituto de Artes, Unicamp, Campinas. 2008. 
Percepção musical e a escola tradicional no brasil: reflexões sobre o ensino e propostas para melhoria no contexto universitário. Campinas, 2013. [344f.] Tese (Doutorado em Música). Instituto de Artes, Unicamp, Campinas, 2013.

PARNCUTT, Richard; McPHERSON, Gary E. The Science and Psychology of Music Performance. New York: Oxford University Press, 2002.

PAZ, E. A. Pedagogia Musical Brasileira no Século XX. Metodologias e Tendências. 2.ed. Brasilia: MusiMed, 2013.

PEREIRA, G. S.; CERQUEIRA, G. M.; SÃO MICUEL, J. A. F. A motivação como ferramenta de aprendizagem significativa. Bahia: lará, 2014. Disponivel em: https://www.recantodasletras.com.br/artigos-deeducacao/4887270 Acesso em: 23 mar. 2019

PROJETO ACADÊMICO DO DEPARTAMENTO DE MÚSICA DA FFLCRPUSP, quinquênio 2019-2023

RAY, S. Os termos pedagogia, didática, ensino, método e técnica na performance musical. In: XXVIII Congresso da Anppom, 2018, Manaus.

RISARTO, M. E.; LIMA, S. A. Capacidades cognitivas e habilidades envolvidas no processo de leitura a primeira vista ao piano. Música em Perspectiva. v. 3, n. 2, p. 87-110, 2010.

SCHAFER, R. M. A Afinação do Mundo: uma exploração pioneira pela história passada e pelo atual estado do mais negligenciado aspecto do nosso ambiente: a paisagem sonora. 2. ed. Traduzido por Marisa T. Fonterrada. São Paulo: Fundação da Editora UNESP, 1977.

SCHAFER, R. M. O Ouvido Pensante. 3.ed. Traduzido por Marisa T. O. Fonterrada. São Paulo: Fundação da Editora da Unesp, 1991.

Educação Sonora. 100 exercícios de escuta e criação de sons. Traduzido por Marisa T. O. Fonterrada. São Paulo: melhoramentos, 2009.

SWANUICK, K. Ensinando Música Musicalmente. Traduzido por Alda Oliveira e Cristina Tourinho. São Paulo: Moderna, 2003. 
TODOROV, J. C.; MOREIRA, M. B. O conceito de motivação na psicologia. Revista

Brasileira de Terapia Comportamental e Cognitiva. São Paulo, v. 7, n. I, p. 1 19-132, 2005. Disponível em: http://pepsic.bvsalud.org/pdf/ rbtcc/v7n l/v7nlal2.pdf Acesso em: 23 mar. 2019

\section{Sobre as autoras}

\section{Cássia Carrascoza Bomfim}

É professora Doutora do Departamento de Música da Faculdade de filosofia, Ciências e Letras de Ribeirão Preto, Universidade de São Paulo - USP. Natural de São Paulo, realizou toda a sua formação acadêmica na ECA - Universidade de São Paulo, obtendo o grau de doutora em 2016. Foi primeira flautista da Orquestra Sinfonica do Teatro Municipal de São Paulo, da Orquestra Jazz Sinfônica do Estado de São Paulo e integrante da Camerata Aberta. Desenvolve um intenso trabalho na pesquisa da performance da música contemporânea brasileira. Atualmente desenvolve pesquisa em performance telemática e improvisação com eletrônica junto ao compositor Paulo C. Chagas e desde dezembro de 2020 é integrante do NowNet Arts Lab Ensemble, grupo internacional, dedicado a performance telemática.

\section{Eliana C. M. G. Sulpício}

Doutora em Musicologia pela ECA-USP; Mestre em Performancel Percussão pela Boston University; Bacharel em Música com Habilitação em Instrumento/Percussão pelo Instituto de Artes do Planalto-UNESP e Graduada em Piano pela UNAERP. Professora do Departamento de Música da FFCLRP-USP e orientadora na Pós-Graduação em Música da ECA-USP. Realiza pesquisa na área de Ciências da Performance e 
áreas correlatas. Atua no In Tempori Duo (duo de Percussão e Trompete com Carlos Sulpício). É fundadora do CRUPURI - Grupo de Percussão do Departamento de Música da FFCLRPUSP, do qual é diretora artística e regente. Fundou também o LAPER, Laboratório de Percussão do DM da FFCLRP-USP, voltado às práticas e pesquisa em Percussão e Rítmica. É líder do Grupo de Pesquisa "Núcleo de Estudos e Pesquisas Multidisciplinares em Artes Musicais do CNPa". Possui várias obras para Percussão e outras formações. Atuou em diversas orquestras e grupos de câmara, no Brasil e Estados Unidos.

\section{Fátima Corvisier}

Natural do Rio de Janeiro, Fátima Corvisier graduou-se com Medalha de Ouro pela Escola de Música da Universidade Federal do Rio de Janeiro. Em 2009, concluiu seu Doutorado pela Universidade de São Paulo (USP), defendendo a tese: Antônio de Sá Pereira e o Ensino Moderno de Piano: pioneirismo na pedagogia pianística brasileira. Como solista, Fátima Corvisier já se apresentou com diversas orquestras brasileiras, destacando-se sua atuação frente à Orquestra Sinfonica do Estado de São Paulo (OSESP), sob a regência do maestro Eleazar de Carvalho. Como recitalista e camerista Fátima Corvisier apresentou-se em muitas salas de concerto pelo Brasil, Estados Unidos e Europa. Suas premiações mais significativas incluem o primeiro lugar no Concurso Nacional de Piano Dirk Bovendorp e o terceiro lugar no III prêmio Eldorado Música. Fátima Corvisier é membro da Academia Nacional de Música do Rio de Janeiro, desde 2012. Desde 1991 a pianista atua intensamente como integrante co-fundadora do Duo Corvisier, ao lado do pianista Fernando Corvisier. O Duo Corvisier é reconhecido como um dos principais duos pianísticos do Brasil por seu entrosamento notável, sua vitalidade rítmica e intensa musicalidade. $O$ Duo Corvisier se apresenta regularmente em muitas salas de concerto do Brasil e do exterior (Argentina, Estados Unidos, Portugal, Espanha, Áustria, 
Inglaterra). Desde 2004, Fátima Corvisier é docente do Departamento de Música da Faculdade de Filosofia, Ciências e Letras de Ribeirão Preto (FFCLRP-USP), onde ministra classes de Piano e Pedagogia do Piano. Como pesquisadora, tem participado de muitos Congressos e Conferencias nacionais e internacionais apresentando trabalhos sobre Pedagogia do Piano e Performance do repertório para duos pianísticos.

\section{Silvia Maria Pires Cabrera Berg}

Natural de São Paulo, após os estudos de graduação em Composição pelo Departamento de Música da Escola de Comunicações e Artes - ECA, da Universidade de São Paulo, através de uma bolsa Capes e do Grupo Ultragaz, realizou estudos e pesquisas na Dinamarca (Universidade de Oslo,) vindo a se radicar na Dinamarca (Universidade de Copenhagen) desenvolvendo pesquisas nas áreas de composição, regência e educação musical, permanecendo nesse país por 24 anos. Foi a primeira Chefe de Departamento do recém fundando Departamento de Música da Faculdade de Filosofia Ciências e Letras de Ribeirão Preto - USP. Desenvolve intensa atividade nas áreas de Composição, Regência e Educação, participando em inúmeros Congressos e Festivais Nacionais e Internacionais. De sua última produção destaca-se O CD Hildegard Now and Then lançado pelo projeto DONNE (Londres) que se encontra disponivel em diversas plataformas online.

Recebido em 24/08/2021

Aprovado em 13/09/2021 